\title{
SIGNIFICANT FACTORS ASSOCIATED WITH THE MENTAL HEALTH OF EARTHQUAKE VICTIMS, CENTERED ON THE CASE OF SOUTH KOREA
}

\author{
LEE KI-YOUNG, LEE YEON-JU, KIM KANG-MIN, KIM HYUN-SUNG \& KIM JAE-HYUN \\ Pusan National University, South Korea
}

\begin{abstract}
The earthquakes that broke out in Gyeongju City in September 2016 were very rare and the largest in size since the country started seismological observation. It has been reported that this disaster caused both physical and psychological problems for Gyeongju residents, and it is on the latter that this study focuses. This research aims to explore the various factors that impact on the psychological health of disaster victims, and suggest a preventive plan to help overcome negative emotional responses to it. 276 subjects were sampled out among the citizens in Gyeongju City who directly experienced the earthquake(s), and they were tested with the BSI-18 (Brief Symptom Inventory). The collected data was statistically analyzed for t-test, ANOVA, and multiple regression analysis to examine the effects of disaster experience upon mental health. The results demonstrated that age, resident type, the perceived seriousness of the disaster, participants' expectations of the government's response to the disaster, and satisfaction with life are variables impacting victim's state of psychological health. Based on the finding, this study proposes preparation of a national crisis control system, regular case management, and making publicly available the government's policy guidelines- along with the results of the disaster response evaluation- as ways to help the victims overcome significant negative emotional responses from disaster experience.

Keywords: disaster, earthquake, BSI, mental health, South Korea.
\end{abstract}

\section{BACKGROUND AND PURPOSE OF RESEARCH}

On the evening of September 12, 2016, two earthquakes happened about 9 kilometers southwest of Gyeongju City - the historical capital, located on the southeastern coast of South Korea. The first earthquake recorded the significant magnitude of 5.1, followed by second, magnitude 5.8 earthquake. This second earthquake has been classified as the strongest tremor in Korean history since the Meteorological Agency started measurements in 1978 [1]. It was unprecedented that three earthquakes greater than 5.0 magnitude happened within a year in Korea, and even two in a row on the same day [2], [3]: one (magnitude of 5.0) near Ulsan waters on July 6th, 2016, and two in Gyeongju City on September 12th, 2016. These earthquakes in Gyeongju City resulted in 23 personal injuries and 1,118 cases of property damage. Furthermore, aftershocks occurred more than 400 times after the main earthquakes. They were sensed throughout the Korean peninsula and the vibration reached parts of neighboring countries such as Nagasaki and Fukuoka in Japan and Shanghai, China [4]. As some experts had maintained that the Korean peninsula was a "safe zone from earthquake", many Korean people expressed anxiety and raised concern over future earthquakes as a source of possible natural disaster.

A disaster, since it is diverse and complex in its characteristic, can cause confusion and problems at a national level, beyond personal and regional level, depending on its type and severity [5]. In particular, the more serious a disaster is, the more likely it is to cause mental damage as well as physical harm to its victims [6]. Natural disasters, for example, lead to physical problems such as headaches, gastrointestinal disturbance, appetite loss [5], and induces diverse psychological problems such as depression, anxiety, paranoia, and 
thoughts of suicide [7]. Among them, depression and anxiety are the most typical and negative emotional responses manifested by a disaster.

Notably, it has been reported that because depression is a common contributing factor in leading disaster victims to suicide, those victims who are more seriously affected by a disaster are more likely to have depression, and disaster-induced depression plays a role in exacerbating stress and increasing the likelihood of suicide [8]. This finding indicates that depression is the one of the most serious negative emotional responses disaster victims are likely to experience. In addition, the study of the psychological characteristics of the victims of the Daegu subway arson attack in 2003 [9] demonstrated that anxiety is more persistent than any other psychological symptoms such as depression and post-traumatic stress disorder, even after a considerable amount of time from the accident. It suggests that the disaster experience can cause such victims to develop conditions of mental illness and result in maladaptive behaviors affecting interaction with others.

In addition, one study analyzing the effect of disaster experience on victims' psychological health [10] found that having an active and positive psychological attitude in coping with disaster experience is an important factor in conquering any resulting anxiety and depression. Although not every victim experiencing a natural disaster will face a serious after effect, he or she is in some way psychologically affected and will respond to a disaster differently depending on his/her socioeconomic and demographic characteristics. And it is known that such demographic factors as gender and age, and the way a person copes with a disaster will have an effect on his or her psychological state of adjustment.

In fact, these findings are supported by a number of domestic and overseas studies. According to a study that surveyed 170 participants who had direct or indirect experience with a disaster - including earthquakes - half suffered mental problems as a result, such as depression or post-traumatic stress disorder (PTSD) [11]. Recent cohort studies abroad also support these findings, discovering that the attack rate of psychological disorders, such as major depressive disorder and post-traumatic stress disorder, significantly increased in victims of earthquake, depending on the extent to which they were exposed to the natural disaster [12]. In addition, direct and indirect victims of a disaster can be afflicted with emotional and psychological problems through a disaster experience. For example, there was a report that the closer people lived to New York during the 9/11 terrorist attack in the United States, the more likely they would experience post-traumatic stress disorder [13].

After experiencing the strong earthquakes of September 2016, Gyeongju City organized 4 psychological support teams of 70 members. These teams have provided residents with various tests to determine the level of depression and stress, as well as basic counseling, in an effort to help the earthquake victims overcome emotional and psychological problems. The local government categorized the victims by the test result, registering those diagnosed as 'high-risk' for case management or helped them to be taken care of in other medical institutions. Further, the local government has helped the victims visit the Mental Health Promotion Center to get psychological counseling with a mental health specialist, available along with a 24/7 careline service. In addition, the central government helps the public with indirect supports such as tax relief, financial support, and reduction of electrical and communication bill in the event they suffer from a natural disaster. However, these benefits are scattered through several institutions, so the victims of a disaster often do not know what documents they should prepare or the institutions they should visit to receive such relief service. Even some of those institutions themselves do not know they have such benefits to offer [14]. As a matter fact, therefore, they are considered as nothing but a nominal supportive system. 
Kang [15] emphasized that it is by far the most important to maintain a legal and institutional system of psychological support for victims having an experience with a disaster to regain psychological stability. In other words, it is necessary for the central government to play a strong role in providing specific and systematic protection and support for disaster victims to recover and promote psychological stability.

Because several of the negative emotional responses that manifest after a traumatic disaster experience can be chronic issues in their daily lives, and as such, lead to suicidal ideation or actual suicide, it is important to explore relevant factors that influence the emotional response of the victims. Only a few precedent studies, however, have focused on the negative relationship between disaster experience and psychological health. Worse still, there is no study that pays attention to the expectations of the government with respect to disaster management and the state of psychological adjustment after a disaster. Such a focus emphasizes the government as an important factor in preventing, preparing for, and coping with a disaster.

Although the recent earthquakes in Gyeongju City were highly risky and dangerous, the government's response was not sufficient, thus intensifying the national confusion around the disaster. Earthquakes carry with them long-lasting risk as a result of the typical three dangerous phases: advance earthquake, main earthquake, and aftershock. Therefore, there is increased urgency to make safety announcements quickly, guide people and take follow-up measures promptly. In addition, the public should be informed of the occurrence and risk of earthquake immediately so that damage can be minimized. In spite of this urgency, an emergency text was sent 9 minutes after the earthquake broke out in the Gyeongju earthquake incident. As a result, the citizens became were panicked and vast numbers tried to access the website of the National Security Agency at the same time, causing the system to go down for 4 hours after the earthquake broke out. This confusion and disruption made it almost impossible to gain necessary information regarding earthquake such as the extent of damage, the presence of aftershock, and countermeasure [16]. Many Korean people argue that national crisis management in the case of disasters has not improved since the Daegu subway fire, the collapse of Seongsu Bridge, and more recently, the Sewol Ferry sinking. These are all considered shameful disasters in Korean history, and pointed to by the public every time a disaster is perceived to have been poorly handled.

Therefore, this study is aimed at exploring various factors that impact on the mental health of victims who experienced a disaster, and suggest a control plan and countermeasures that the government can take to effectively prevent, treat, and help disaster victims overcome negative emotional reactions.

\section{RESEARCH METHOD}

\subsection{Research subjects and date collection}

The population of this survey are the residents in Gyeongju, who directly experienced the earthquake(s) that occurred in September 2016. The employees in the local social welfare centers and college/university students, as well as ordinary citizens aged over 30 were chosen by convenient sampling technique. A total of 350 questionnaires were distributed and 310 were collected over November and December 2016. 34 questionnaires were excluded due to insincere responses, leaving 276 questionnaires for final analysis. 


\subsection{Variables and measurements}

This study used a structured questionnaire. It consists of 31 questions in total: 5 questions of demographic characteristics; 3 of experience with earthquake; 5 of satisfaction with life; and 18 BSI-18 [17] questions. BSI was employed to measure the state of mental health, which was set as the response variable. BSI-18 - used for this study - is a simplified symptom diagnosis tool which is based on the standardized SCL-90-R scale developed by Derogatis and colleagues [18].

This inventory consists of 18 questions: 6 questions of somatization (consciousness of cardiovascular disorder, gastrointestinal disorder, and other physiological symptoms); 6 questions of depression (unpleasant negative feelings such as despair, self-depreciation, and suicide); and 6 questions of anxiety (psychological instability such as tension and edginess including various symptoms of panic disorder). In the study of Park and Kippeum [19], Cronbach's $\alpha$ of BSI was 0.89 , and that of its sub-factors revealed the following figures: somatization (0.73), depression (0.80), and anxiety (0.81). In this study, Cronbach's $\alpha$ of overall BSI was 0.971 , and that of its sub-factors were somatization (0.940), depression (0.926), and anxiety (0.934). Table 1 shows the details of each variable.

Table 1: Structure and composition of questionnaire.

\begin{tabular}{|l|l|l|}
\hline $\begin{array}{l}\text { Area of } \\
\text { Measurement }\end{array}$ & Detailed Items & $\begin{array}{l}\text { Number of } \\
\text { Questions }\end{array}$ \\
\hline $\begin{array}{l}\text { Demographic } \\
\text { variables }\end{array}$ & $\begin{array}{l}\text { 1. Gender: M/F } \\
\text { 3. Age: In their 20s/30s/40s/50s/60s or older } \\
\text { middle school, high school, college/university } \\
\text { 4. Housing type: owned/leased/monthly rent/other } \\
\text { 5. Family living together: } \\
\text { Alone/spouse/parent(s)/child(ren)/brother(s) sister(s)/ } \\
\text { other }\end{array}$ & 5 \\
\hline $\begin{array}{l}\text { Experience } \\
\text { with } \\
\text { earthquake }\end{array}$ & $\begin{array}{l}\text { 6. Damage to property: damage to personal property due } \\
\text { to earthquake } \\
\text { 7. Seriousness: How serious do you think these } \\
\text { earthquakes were? 5-point scale } \\
\text { 8. Expectation from the government: Expectation for } \\
\text { government to take follow-up measure when earthquake } \\
\text { broke out. 5-point scale }\end{array}$ & 3 \\
\hline $\begin{array}{l}\text { Satisfaction } \\
\text { with life }\end{array}$ & $\begin{array}{l}\text { 9-13. How satisfied are you with your daily life? (with 5 } \\
\text { elements, respectively: income, health, family, } \\
\text { neighbors, and overall) 5-point scale }\end{array}$ & 5 \\
\hline BSI-18 & $\begin{array}{l}\text { 14. State of psychological adjustment: how much (the } \\
\text { extent of symptom) did you experience these 3 sub } \\
\text { factors (somatization, depression, and anxiety), } \\
\text { respectively, for a week after the earthquake? 5-point } \\
\text { scale }\end{array}$ & 18 \\
\hline
\end{tabular}




\subsection{Data analysis}

The collected data was analyzed using SPSS 22.0 program. First, mean and standard deviation were computed to examine demographic characteristics while frequency and percentage were calculated for other items. To test difference between the variables, t-test and ANOVA were conducted. In addition, multiple regression analysis, for which BSI was set as the dependent variable, was carried out to find the factors affecting the independent variable. Critical value for all statistical significance was set at $\mathrm{p}<0.05$.

\section{RESULTS}

\subsection{Difference in mental health by demographic characteristic}

The demographic characteristics of the respondents were examined for 5 categories: gender, age, education, housing type, and family structure. Female respondents $(\mathrm{N}=160,57.3 \%)$ were more than male ones $(\mathrm{N}=119,42.7 \%) .5$ age groups were composed in this order: $50 \mathrm{~s}$ $(\mathrm{N}=72,25.8 \%), 20 \mathrm{~s}(\mathrm{~N}=60,21.5 \%), 60 \mathrm{~s}$ and older $(\mathrm{N}=54,19.4 \%), 30 \mathrm{~s}(\mathrm{~N}=47,16.8 \%)$, and $40 \mathrm{~s}(\mathrm{~N}=46,16.5 \%)$. For educational level, high school graduate $(\mathrm{N}=131,47.3 \%)$ was the largest in number and followed by college graduate or higher $(\mathrm{N}=112,40.4 \%)$. On the other hand, only 30 respondents composed participants with no-education $(\mathrm{N}=2,0.7 \%)$, primary school graduate $(\mathrm{N}=4,5.1 \%)$, and middle school graduate $(\mathrm{N}=18.6 .5 \%)$. Therefore, there was doubt they could not form normal distribution, so they were not directly used for multiple regression analysis. By housing type, house owner took the most $(\mathrm{N}=188,67.9 \%)$ and was followed by lease $(\mathrm{N}=31,11.2 \%)$ and monthly rent $(\mathrm{N}=30,10.8 \%)$. Since housing prices are much higher than income (wage) and other prices in Korea, it is safe to say that most of the Korean people set their sights on owning a house. Therefore, whether to own a house or not was set as independent variable in multiple regression model. Last, multiple response was allowed for answering about family member to live with. As a result, spouse was the most selected answer $(\mathrm{N}=150,13.8 \%)$, which was followed by children $(\mathrm{N}=80,21.3 \%)$. Living with a parent $(\mathrm{N}=55,14.6 \%)$, and living alone $(\mathrm{N}=52,13.8 \%)$ turned out to be similar proportions. And siblings (brother and sister) was least selected. For t-test for the mean difference between groups, and regression analysis, family structure was grouped into two: living alone and living together.

The respondents were grouped by demographic characteristic ( 5 groups) and divided by experience of damaged property (yes/no) after earthquake. And then the factors having impact on their mental health state were examined. The results showed there was a significant difference in mental health state by age. Those in their 20s and 30s had mean of 2.18 and 2.13 , respectively, but the other age groups showed a higher mean as they are older: thus, those in their $60 \mathrm{~s}$ and older showed the worse state of mental health (2.6). In other words, the older the age group, the higher the mean of mental health state was, except for those in their 20s. By education, middle school graduates or those with lower education had higher mean of mental health state, which is statistically significant. In addition, the mean was the lowest in-house owner group while the highest in house lease group. On the other hand, the state of mental health wasn't significantly different by gender (M/F), living type (alone/together), and damage to property $(\mathrm{Y} / \mathrm{N})$. However, it was found that male group, living-alone group, and damaged property group had the worse state of mental health than female group, livingtogether group, and undamaged property group. 
Table 2: Difference in mental health by demographic characteristic.

\begin{tabular}{|c|c|c|c|c|}
\hline \multirow{2}{*}{ Variable } & \multirow{2}{*}{ Categories(N) } & \multicolumn{3}{|l|}{ BSI_ } \\
\hline & & Mean & $\mathrm{t} / \mathrm{F}$ & $\mathrm{p}$-value \\
\hline \multirow{2}{*}{ Gender } & Male (119) & $2.37( \pm 1.05)$ & \multirow{2}{*}{0.697} & \multirow{2}{*}{0.487} \\
\hline & Female (160) & $2.29( \pm 0.74)$ & & \\
\hline \multirow{5}{*}{ Age } & $20 \mathrm{~s}(60)$ & $2.18( \pm 0.89)$ & \multirow{5}{*}{2.658} & \multirow{5}{*}{0.033} \\
\hline & $30 s(47)$ & $2.13( \pm 0.82)$ & & \\
\hline & $40 s(46)$ & $2.34( \pm 0.90)$ & & \\
\hline & $50 \mathrm{~s}(72)$ & $2.43( \pm 0.91)$ & & \\
\hline & 60 s or older $(54)$ & $2.60( \pm 0.86)$ & & \\
\hline \multirow{5}{*}{ Education } & None (2) & $3.11( \pm 0.31)$ & \multirow{5}{*}{6.559} & \multirow{5}{*}{0.000} \\
\hline & $\begin{array}{l}\text { Primary school } \\
\text { graduate (14) }\end{array}$ & $2.74( \pm 0.84)$ & & \\
\hline & $\begin{array}{l}\text { Middle school } \\
\text { graduate (18) }\end{array}$ & $3.22( \pm 1.17)$ & & \\
\hline & $\begin{array}{l}\text { High school } \\
\text { graduate (131) }\end{array}$ & $2.25( \pm 0.91)$ & & \\
\hline & $\begin{array}{l}\text { College graduate } \\
\text { or higher (112) }\end{array}$ & $2.33( \pm 0.89)$ & & \\
\hline \multirow{4}{*}{$\begin{array}{l}\text { Housing } \\
\text { ownership }\end{array}$} & Owned (188) & $2.25( \pm 0.80)$ & \multirow{4}{*}{3.052} & \multirow{4}{*}{0.029} \\
\hline & Leased (31) & $2.70( \pm 1.14)$ & & \\
\hline & Monthly rent (30) & $2.56( \pm 1.05)$ & & \\
\hline & Other (28) & $2.24( \pm 0.88)$ & & \\
\hline \multirow{2}{*}{ Living alone } & Yes (52) & $2.32( \pm 1.08)$ & \multirow{2}{*}{0.858} & \multirow{2}{*}{0.394} \\
\hline & No (227) & $2.19( \pm 0.87)$ & & \\
\hline \multirow{2}{*}{$\begin{array}{l}\text { Damage to } \\
\text { property }\end{array}$} & Yes (81) & $2.48( \pm 0.85)$ & \multirow{2}{*}{1.850} & \multirow{2}{*}{0.065} \\
\hline & No (198) & $2.26( \pm 0.90)$ & & \\
\hline
\end{tabular}

\subsection{Factors that affect upon mental health}

Multiple regression analysis was carried out to find the factors to affect the mental health state of the subjects and Table 3 shows the results. Here, categorical variable was set as dummy variable. Judging from VIF $(1.110 \sim 1.578)$, which turned out to be less than 10 , this model could be considered not having multicollinearity. And Durbin-Watson value was 1.867 , which means error terms were independent enough from each other.

The results of multiple regression analysis showed that age $\left(\beta=0.175^{*}\right)$ and house owner $\left(\beta=0.190^{* *}\right)$, among the demographic characteristics, had a significant impact on the state of mental health. Of experience variables related to a disaster, perceived seriousness 
( $\beta=0.194 * *)$ and expectation of the government $(\beta=0.152 *)$ during earthquake turned out to have significant impacts on the state of mental health. And satisfaction with daily life ( $\left.\beta=0.226^{* * *}\right)$ proved to have the highest impact on the state of mental health among input variables. Here, the exploratory power of the model was $16 \%$. As mentioned earlier, the measuring tool for mental health state could be sub-divided into somatization, depression, and anxiety, and each mean could be used, but the mean of the sum of the three items was same, so the mean of the sum was set as one dependent variable. Mental health measuring instrument used in this study allows measurement of somatization, depression and anxiety individually. The value from dividing the sum by three equals the individually calculated average. For this reason, the average from dividing the sum by three is the dependent variable. In summary, it proved out that as the respondents were older, they came to expect more from the government after earthquake and took earthquakes more seriously. They experienced more of a negative impact on mental health state while owning a house and high satisfaction with daily life had a positive impact on the participants' condition.

\section{DISCUSSION AND CONCLUSION}

The present study carried out a survey with 276 residents in their 20s or older in Gyeongju City who experienced two earthquakes on September 12th, 2016, and analyzed the factors that affect their mental health. The results are detailed in the following.

When the mean of mental health state was set as responsive variable, it showed a significant difference by age, education, and housing type. This result supports the finding of

Table 3: Factors that affect upon mental health (multiple regression analysis).

\begin{tabular}{|l|l|l|l|}
\hline $\begin{array}{l}\text { Variable } \\
(* \text { dummy variable) }\end{array}$ & $\beta$ & $\mathrm{t}$ & $\mathrm{p}$-value \\
\hline Constant & & 3.718 & 0.000 \\
\hline Gender (male)* & 0.024 & 0.407 & 0.685 \\
\hline Age & 0.175 & 2.440 & 0.015 \\
\hline $\begin{array}{l}\text { Education (college } \\
\text { graduate or higher) }\end{array}$ & 0.021 & 0.344 & 0.731 \\
\hline $\begin{array}{l}\text { Housing ownership } \\
\text { (owned) } *\end{array}$ & -0.190 & -2.754 & 0.006 \\
\hline Living alone(yes) $*$ & -0.026 & -0.395 & 0.693 \\
\hline $\begin{array}{l}\text { Damage to property } \\
\text { (yes) } *\end{array}$ & 0.060 & 0.968 & 0.334 \\
\hline Satisfaction with life & -0.226 & -3.645 & 0.000 \\
\hline $\begin{array}{l}\text { Expectation from the } \\
\text { government }\end{array}$ & 0.152 & 2.349 & 0.020 \\
\hline Seriousness & 0.194 & 3.106 & 0.002 \\
\hline $\mathrm{R}^{2}=0.163$, Adjusted $\mathrm{R}^{2}=0.134$, Durbin-Watson=1.867, F=5.575, $\mathrm{p}=0.000$ \\
\hline
\end{tabular}


Cho and Yang [21] that as people get older, their symptoms of depression and anxiety get worse. By the level of education, it was hard to say that the resultant difference was accurate enough because those of no education, primary school graduates, and middle school graduates were relatively smaller in number. However, they showed higher mean than that of high school graduates and college/university graduates. Therefore, it can be considered that education level has an impact on the state of mental health. Last, by housing type, those who live in leased house showed the highest mean of mental health state. As mentioned before, house ownership is an important demographic characteristic because it is impossible to purchase a house in Korea, even with one's life savings, without financial support from parents. It indicates economic level or situation can have impact on mental health state of disaster victims.

To find more factors that affect overall state of mental health earthquake victims, this study put additional variables in the model: so, the total variables consisted of demographic characteristics, damaged/undamaged property, satisfaction with life, expectation for the government, and perceived seriousness of the earthquakes. As a result, this model revealed the significant impacts of age, house ownership, satisfaction with life, expectation for the government, and perceived seriousness of the earthquakes on mental health state. In other words, we observed that when the respondents were older; expected more from the government after the earthquakes; took the earthquakes more seriously; are less satisfied with their daily life; and do not own a house, they have a more negative state of mental health. Comparing the beta values, it can be known that satisfaction with daily life has the greatest impact on mental health state among other variables. The extent of the impact that the other variables have are as follows in this order: perceived seriousness, house ownership, age, expectation from the government. In Korean society, trust on the government has fallen to the bottom, which has naturally led to the national anxiety experienced after the earthquakes. Therefore, we can still consider that expectations of the government play an important role for victims of a disaster.

Based on these findings, we can put forth the following points for discussion.

1. It is imperative to put a national crisis response system in place to dismiss the public anxiety. As Kang [16] suggested, it is important to develop a preventive manual for victims of a disaster and provide them with safety education in order to help them secure psychological stability. However, more important is that the government establishes or improves a legally mandatory system that can minimize secondary damages, such as depression, anxiety and suicide, by taking swift and accurate measures after earthquakes break out.

2. A number of studies confirmed that those who have experienced a disaster have more serious psychological maladjustment as time goes by [21]. This result indicates the need for a long-term project to solve the psychological and emotional problems of victims of disasters. It requires an effort to minimize damage through a long-term and regular care service, rather than one-time or temporary psychological evaluation or case management.

3. The government should present the public with an innovative road map and policy for preventive and protective measures against disaster, and make an effort to evaluate how such efforts work out every year. If it does not open its long-term policy guidelines and evaluation results to the public, it will be hard to restore public trust given the Korean people's long held distrust of the government. The public trust of the government, particularly for taking and executing disaster countermeasures, is a very important element for the national mental health as a whole. Therefore, future studies should continue examining the importance of this factor. 


\section{REFERENCES}

[1] The Segye Times, 5.8 Additional Magnitude, Online. http://www.segye.com.

[2] HYUNDAENEWS, Nuclear Super-Density Areas, Korea: Terrible.

[3] Imagination of 'Earthquake', http://www.hyundaenews.com.

[4] YTN, Ministry of Public Safety and Security Describe the Damage Situation of Gyeongju Earthquake, Online. www.ytn.co.kr.

[5] Energy economy, Gyeongju Earthquake Injured 23 People, Online. http://www.ekn.kr.

[6] Bae, J., Kim, H., Park, H., Shin, H., Hong, H. \& Sohn, H., A Study on Floor Disaster Experience Analysis for Psychological Support Strategy Development. Crisisonomy, 11(9), pp. 23-45, 2015.

[7] Tsutsumi, A., Izutsu, T., Ito, A., Thornicroft, G., Patel, V. \& Minas, H., Mental Health Mainstreamed in New UN Disaster Framework. The Lancet. Psychiatry, 2(8), pp. 679-680, 2015.

[8] Kim, D. \& Lee, J., The Change in the Life of Island Residents after An Oil Spill Accident by the Herbei Spirit - Focusing on Gaui-do(island), Taean-gun. ECO: The Korean Journal of Environmental Sociology, 12(2), pp. 119-152, 2008.

[9] Kim, M., Kim, S. \& Kim, K., Effects of Negative Emotion Experience and Suicide Ideation from Traumatic Events on Subjective Well-being: Moderating Effect of Selfdisclosure. Korean Journal of Clinical Psychology, 34(1), pp. 249-270, 2015.

[10] Ha, S., Suh, S., Kim, J. \& Lee, E., Psychiatric Characteristics of Wounded Persons of Daegu Subway Fire Accident after Six Years. Anxiety and Mood, 5(2), pp. 125-132, 2009.

[11] Kim, K., Kim, S. \& Kwon, S., Changing Patterns of Psychological Maladaptive Symptoms after Hebei Spirit Oil Spill for Three Years: Focused on a Damaged Regional Comparison, The Korean Journal of Health Psychology, 17(4), pp. 10451065, 2012.

[12] NEWSIS, One Person of the Two Person who had Experienced Earthquake and Disaster had Serous Disaster Trauma, Online. http://www.newsis.com. Accessed on: 21 Sep. 2016.

[13] Fergusson, D.M., Horwood, L.J., Boden, J.M. \& Mulder, R.T., Impact of a Major Disaster on the Mental Health of a well-studied Cohort. JAMA Psychiatry, 71(9), pp. 1025-1031, 2014.

[14] Hong, J., "Need for Trauma Healing Systems", 2016.

[15] Seo, J. \& Cho, W., A Study on the Relief Service Promotion Plan for Natural Disaster Victims. Korean Society of Disaster \& Security, 6(2), pp. 15-22, 2013.

[16] Kang, Y., An Analysis of Psychological Support of Disaster Victims of Jeju Special Self-Governing Province in Terms of Typhoon "Nari". TamlaMunwha, 38, pp. 279307, 2011.

[17] Ecomedia, People has Impatiented for Kyung Earthquake, Government Respond with Late, Online. http://www.ecomeddia.com. Accessed on: 13 Sep. 2016.

[18] Derogatis, L.R., Lipman, R.S. \& Covi, L., SCL-90: An Outpatient Psychiatric Rating Scale - Preliminary Report. Psychopharmacology Bulletin, 1(1), pp. 13-28, 1973.

[19] Derogatis, L.R., Brief Symptom Inventory (BSI)-18. Administration, Scoring and Procedures Manual. NCS Pearson: Minneapolis, 2001.

[20] Park, K., Woo, S. \& Chang, M., Validational Study of Brief Symptoms Inventory18(BSI-18) in College Students. Korean Journal of Clinical Psychology, 31(2), pp. 507-521, 2012. 
112 Disaster Management and Human Health Risk V

[21] Cho, Y. \& Yang, S., Peri-Traumatic Dissociation, Post-Traumatic Negative Beliefs and Poor Social Support as Predictors of Long-Term Psychological Symptoms Following a Natural Disaster. Korean Journal of Clinical Psychology, 32(4), pp. 955-979, 2013.

[22] Kim, S., Kim, K. \& Kwon, S., Stress and Gambling Behavior of Taean Residents Experiencing Disaster: Mediating Effect of Negative Affects. The Korean Psychological Association, 1, pp. 340-341, 2012. 